\title{
Surgical resection for hepatic metastasis from gastric cancer: a multi- institution study
}

\author{
Ailin Song ${ }^{1}$, Xiaofeng Zhang ${ }^{2}$, Feng Yư ${ }^{3}$, Debang $\mathbf{L i}^{4}$, Wenyu Shao ${ }^{5}$, Yanming Zhou ${ }^{6}$ \\ ${ }^{1}$ Department of General Surgery, Second Hospital of Lanzhou University, Lanzhou, China \\ ${ }^{2}$ Department of Special Treatment, Eastern Hepatobiliary Surgery Hospital, Second Military Medical University, Shanghai, \\ China \\ ${ }^{3}$ Department of Hepatobiliary Surgery, the 101th Hospital of Chinese PLA, Wuxi, China \\ ${ }^{4}$ Department of General Surgery, First Hospital of Lanzhou University, Lanzhou, China \\ ${ }^{5}$ Department of Liver Surgery, First Affiliated Hospital of Nanjing Medical University, Nanjing, China \\ ${ }^{6}$ Department of Hepatobiliary and Pancreatovascular Surgery, First Affiliated Hospital of Xiamen University, Xiamen, China
}

Correspondence to: Yanming Zhou, email: zhouymsxy@sina.cn

Keywords: gastric cancer, liver metastases, hepatectomy, prognosis

Received: January 02, $2017 \quad$ Accepted: March 21, $2017 \quad$ Published: March 30, 2017

Copyright: Song et al. This is an open-access article distributed under the terms of the Creative Commons Attribution License 3.0 (CC BY 3.0), which permits unrestricted use, distribution, and reproduction in any medium, provided the original author and source are credited.

\section{ABSTRACT}

Background: The beneficial effect of surgical resection for hepatic metastasis from gastric cancer (HMGC) remains elusive. This study was conducted to analyze surgical outcomes of HMGC and determine the prognostic factors associated with survival.

Results: The in-hospital mortality rate was zero, and the overall morbidity rate was $56 \%$. The overall $1-, 3$-, and 5 -year survival rate after surgery was $87.5 \%$, $47.6 \%$, and $21.7 \%$, respectively, with a median survival time of 34.0 months. Multiple liver metastases (hazard ratio $[\mathrm{HR}]=1.998 ; 95 \%$ confidence interval $[\mathrm{CI}]=1.248$ $3.198 ; P=0.004)$ and $\geq$ T3 stage of the primary gastric cancer $(H R=2.065 ; 95 \%$ CI $=1.201-3.549 ; P=0.009)$ were independent prognostic determinants in the multivariate analysis.

Materials and Methods: Data on surgical resection of 96 patients with HMGC at six institutions in China were analysed retrospectively. Prognostic factors were assessed by multiple stepwise regression analysis using the Cox model.

Conclusions: Surgical resection for HMGC is feasible and beneficial to long-term survival in selected patients.

\section{INTRODUCTION}

It was reported that about $14 \%$ gastric cancer patients developed hepatic metastasis, and more than $30 \%$ gastric cancer patients developed metachronous liver metastasis after surgical resection of the primary gastric cancer [1]. Although previous studies [2-32] reported that hepatectomy may provide an opportunity of long-term survival in these patients (Table 1), most of these studies were conducted on the single-institution basis including no more than 50 cases, and therefore the beneficial effect of hepatectomy are not well-defined. The objective of this study was to analyze the outcome of surgical resection of hepatic metastasis from gastric cancer (HMGC) and determine prognostic factors associated with survival in a relatively large multi-institution cohort of patients.

\section{RESULTS}

Patient characteristics

The study group included 72 (75\%) men and 24 $(25 \%)$ woman with a median age of 63 (range 32-78) years. Of these, $59(61.5 \%)$ patients presented with synchronous liver metastases and $37(38.5 \%)$ presented with metachronous liver metastases. In the latter group, the median interval between gastrectomy and hepatectomy for hepatic metastasis was 8.7 months (range, 4-32 months). Forty-two $(43.7 \%)$ patients presented with solitary lesions, and $54(56.3 \%)$ had multiple lesions. Ninety-one (94.8\%) patients achieved curative resection. Fifty-eight $(60.4 \%)$ patients received adjuvant therapy after hepetectomy. 
Table 1: Literature overview of outcomes following hepatectomy for metastatic gastric cancer

\begin{tabular}{|c|c|c|c|c|c|c|c|c|}
\hline Reference & Year & Country & $\begin{array}{c}\text { Study } \\
\text { interval }\end{array}$ & $\begin{array}{c}\text { No. of } \\
\text { patients }\end{array}$ & $\begin{array}{c}\text { Mortality } \\
(\%)\end{array}$ & $\begin{array}{c}\text { 3-year } \\
\text { OS (\%) }\end{array}$ & $\begin{array}{c}\text { 5-year } \\
\text { OS (\%) }\end{array}$ & $\begin{array}{c}\text { MST } \\
\text { (months }\end{array}$ \\
\hline Ambiru et al. [2] & 2001 & Japan & 1975-1999 & 48 & 0 & - & 18 & 12 \\
\hline Imamura et al. [3] & 2001 & Japan & 1990-1997 & 17 & 0 & 22 & 0 & - \\
\hline Okano et al. [4] & 2002 & Japan & 1986-1999 & 19 & 0 & 34 & 34 & - \\
\hline Zacherl et al. [5] & 2002 & Austria & 1980-1999 & 15 & 6.7 & 14.3 & 0 & 8.8 \\
\hline Sakamoto et al. [6] & 2003 & Japan & 1985-2001 & 22 & 5 & 38 & 38 & 21 \\
\hline Shirabe et al. [7] & 2003 & Japan & 1979-2001 & 36 & 0 & 26 & 26 & - \\
\hline Adam et al. [8] & 2006 & France & 1983-2004 & 64 & - & - & 27 & 15 \\
\hline Sakamoto et al. [9] & 2007 & Japan & 1990-2005 & 37 & 0 & - & 11 & 31 \\
\hline Cheon et al. [10] & 2008 & Korea & $1995-2005$ & 41 & 3 & 31.7 & 20.8 & 17 \\
\hline Morise et al. [11] & 2008 & Japan & 1989-2004 & 18 & 0 & 27 & 27 & 13 \\
\hline Thelen et al. [12] & 2008 & Germany & 1988-2002 & 24 & 4.2 & 22 & 15 & 10 \\
\hline Ueda et al. [13] & 2009 & Japan & 1991-2005 & 15 & 0 & 60 & 60 & - \\
\hline Makino et al. [14] & 2010 & Japan & 1992-2007 & 16 & 0 & 46.4 & 37.1 & 38.3 \\
\hline Tsujimoto et al. [15] & 2010 & Japan & 1980-2007 & 17 & 0 & 37.5 & 31.5 & 34 \\
\hline Dittmar et al. [16] & 2012 & Germany & 1995-2009 & 15 & 0 & 54 & 27 & 48 \\
\hline Garancini et al. [17] & 2012 & Italy & 1998-2007 & 21 & 0 & 31 & 19 & 11 \\
\hline Miki et al. [18] & 2012 & Japan & 1995-2009 & 25 & - & 42.8 & 36.7 & 33.4 \\
\hline Schildberg et al.19] & 2012 & Germany & $1972-2008$ & 31 & 6 & 25 & 13 & 14 \\
\hline Takemur et al. [20] & 2012 & Japan & 1993-2011 & 64 & 0 & 50 & 37 & 34 \\
\hline Wang et al. [21] & 2012 & China & 2003-2008 & 30 & 0 & 16.7 & 16.7 & 11 \\
\hline Baek et al. [22] & 2013 & Korea & 2003-2010 & 12 & 0 & 39 & 39 & 31 \\
\hline Chen et al. [23] & 2013 & China & $2007-2012$ & 20 & 0 & 20 & - & 22.3 \\
\hline Qiu et al. [24] & 2013 & China & 1998-2009 & 25 & 0 & 70.4 & 29.4 & 38 \\
\hline Komeda et al. [25] & 2014 & Japan & $2000-2012$ & 24 & 0 & 40.1 & 40.1 & 22.3 \\
\hline Wang et al. [26] & 2014 & China & 1996-2008 & 35 & 0 & 17.9 & 10.3 & 14 \\
\hline Kinoshita et al. [27] & 2015 & Japan & 1990-2010 & 256 & 1.6 & 77.3 & 41.9 & 31.1 \\
\hline Shinohara et al. [28] & 2015 & Japan & 1995-2010 & 19 & 0 & 31.7 & 31.7 & 27 \\
\hline Tiberio et al. [29] & 2015 & Italy & 1997-2011 & 53 & - & 14 & 9.3 & 13 \\
\hline Oki et al. [30] & 2016 & Japan & $2000-2010$ & 94 & - & 51.4 & 42.3 & 40.8 \\
\hline Tiberio et al. [31] & 2016 & Italy & 1990-2013 & 105 & 0.9 & 20.3 & 13.1 & 14.6 \\
\hline Markar et al. [32] & 2017 & UK & 1997-2012 & 78 & 10.3 & 42 & 31 & - \\
\hline
\end{tabular}

Abbreviations: MST = median survival time; OS = overall survival.

\section{Results of surgical resection}

There was no intra- or postoperative mortality. A total of 63 complications occurred in 46 patients $(47.9 \%)$, of whom $11(11.4 \%)$ patients had major morbidities (Clavien-Dindo $\geq 3 \mathrm{a}$ ).

During the median follow-up period of 33 months, $77(80.2 \%)$ patients experienced recurrences. The most frequently site of recurrence was the liver $(n=45,58.4 \%)$, followed by the lymph node $(n=11,14.3 \%)$, peritoneum $(n=8,10.3 \%)$, and lung $(n=8,10.3 \%)$. Details of the recurrences were unknown in 5 cases $(6.5 \%)$. Only 3
(6.7\%) of the 45 patients with liver recurrences underwent re-hepatectomy.

The 1-, 3- and 5-year overall survival (OS) rate of the entire cohort of patients after surgery was $87.5 \%$, $47.6 \%$ and $21.7 \%$, respectively, with a median survival time of 34.0 months (Figure 1). Several factors were found to be associated with poor prognosis in univariate analysis (Table 2). Multiple liver metastases (hazard ratio [HR] $=1.998 ; 95 \%$ confidence interval $[\mathrm{CI}]=1.248-3.198$; $P=0.004)$ and $\geq \mathrm{T} 3$ stage of the primary gastric cancer $(\mathrm{HR}=$ $2.065 ; 95 \% \mathrm{CI}=1.201-3.549 ; P=0.009)$ were independent prognostic determinants, as shown by multivariate analysis. 


\begin{tabular}{|c|c|c|c|}
\hline Variables & Number & MST (months) & $P$-value \\
\hline \multicolumn{4}{|l|}{ Gender } \\
\hline Male & 72 & 40 & 0.714 \\
\hline Female & 24 & 28 & \\
\hline \multicolumn{4}{|l|}{ Age } \\
\hline$\geq 65$ & 51 & 36 & 0.739 \\
\hline$<65$ & 45 & 34 & \\
\hline \multicolumn{4}{|l|}{ T stage of gastric cancer } \\
\hline$<\mathrm{T} 3$ & 47 & 46 & 0.007 \\
\hline$\geq \mathrm{T} 3$ & 59 & 24 & \\
\hline \multicolumn{4}{|l|}{ Lymph node status of gastric cancer } \\
\hline N0-N1 & 28 & 45 & 0.015 \\
\hline N2-N3 & 68 & 30 & \\
\hline \multicolumn{4}{|l|}{ Histologic grade of gastric cancer } \\
\hline Well-moderate & 62 & 42 & 0.032 \\
\hline Poorly & 34 & 29 & \\
\hline \multicolumn{4}{|l|}{ Histologic type of gastric cancer } \\
\hline Intestinal & 61 & 44 & 0.058 \\
\hline Diffuse & 12 & 17 & \\
\hline \multicolumn{4}{|l|}{ Type of gastrectomy } \\
\hline Total gastrectomy & 33 & 22 & 0.373 \\
\hline Subtotal gastrectomy & 63 & 40 & \\
\hline \multicolumn{4}{|l|}{ Timing of hepatic metastasis } \\
\hline Synchronous & 59 & 43 & 0.167 \\
\hline Metachronous & 37 & 33 & \\
\hline \multicolumn{4}{|l|}{ Type of hepatectomy } \\
\hline Major ( $\geq 3$ segments) & 35 & 34 & 0.456 \\
\hline Minor ( $<3$ segments) & 61 & 36 & \\
\hline \multicolumn{4}{|l|}{ Curative resection } \\
\hline Yes & 91 & 39 & 0.031 \\
\hline No & 5 & 27 & \\
\hline \multicolumn{4}{|l|}{ Maximum hepatic metastasis size } \\
\hline$<5 \mathrm{~cm}$ & 71 & 44 & 0.069 \\
\hline$\geq 5 \mathrm{~cm}$ & 25 & 28 & \\
\hline \multicolumn{4}{|l|}{ Number of metastases } \\
\hline Solitary & 42 & 42 & 0.021 \\
\hline Multiple & 54 & 29 & \\
\hline \multicolumn{4}{|l|}{ Distribution of liver metastases } \\
\hline Unilobar & 57 & 41 & 0.394 \\
\hline Bilobar & 29 & 32 & \\
\hline \multicolumn{4}{|l|}{ Morbidity } \\
\hline Yes & 46 & 40 & 0.237 \\
\hline No & 50 & 31 & \\
\hline \multicolumn{4}{|l|}{ Adjuvant chemotherapy } \\
\hline Yes & 58 & 42 & 0.172 \\
\hline No & 38 & 35 & \\
\hline
\end{tabular}

Abbreviations: $\mathrm{MST}=$ median survival time. 


\section{DISCUSSION}

Although solid clinical evidence exists to support surgical resection as the optimal option for the treatment of colorectal liver metastasis (CLM), data evaluating the postoperative outcome of HMGC are limited and controversial (Table 1). This may be explained by the fact that most patients with HMGC presented with multiple lobar metastases, gross peritoneal dissemination, extensive lymph node metastases, distant metastasis, or direct invasion to other organs at time of diagnosis, and therefore were considered unamenable to surgery [5]. It was reported that patients with potentially resectable HMGC treated with systemic chemotherapy had a median survival of 5.5 months, and the number of 3-year survivors was zero [23]. A systematic review of 870 patients from 23 studies performed by Petrelli and colleagues in 2015 demonstrated that resection of HMGC was associated with a 22-month median survival and a $23.8 \% 5$-year OS rate [33]. A similar systematic review was published by Markar et al in 2016, which included 991 patients and come to similar conclusions, with a median 5-year OS of $27 \%$ [34]. In accordance with these two reports, the present study also confirmed the benefit of surgical resection for HMGC in achieving longterm survival in a relatively large cohort of patients drawn from multi-centers in China. The 5-year OS rate after surgery was $21.7 \%$ with a median survival time of 34.0 months.

Safety is an important concern in such an aggressive management strategy. Hepatic resection of metachronous liver disease is technically demanding because of intraabdominal adhesions caused by previous surgery. Synchronous resection of the HMGC and primary tumor may be associated with increased post-operative complications. However, in the present study and previous reports, resection could be safely performed with acceptable operative mortality and morbidity [19-28]. It should be noted that this favourable outcome may be attributed to careful selection of patients with limited disease, as reflected by major hepatectomy is not performed frequently [27]. In addition, patients with HMGC usually had no underlying cirrhosis, a factor associated with a high risk of postoperative liver failure because of the limited regenerative capacity of the liver remnant.

Multivariate analysis in our series disclosed that multiple liver metastases and $\geq \mathrm{T} 3$ stage of the primary gastric cancer were independent prognostic determinants. These data may have important implications in helping select patients for surgical resection. There is evidence that postoperative complications, especially major complications, have a negative impact on long-term survival after oncological surgery [35]. Immunosuppression secondary to septic complications may increase the growth of occult micrometastasis, and some complications may make patients unfit for adjuvant therapy or delay the time interval. However, we did not find that OS was significantly reduced in patients with complications in our study. The fact that there were only

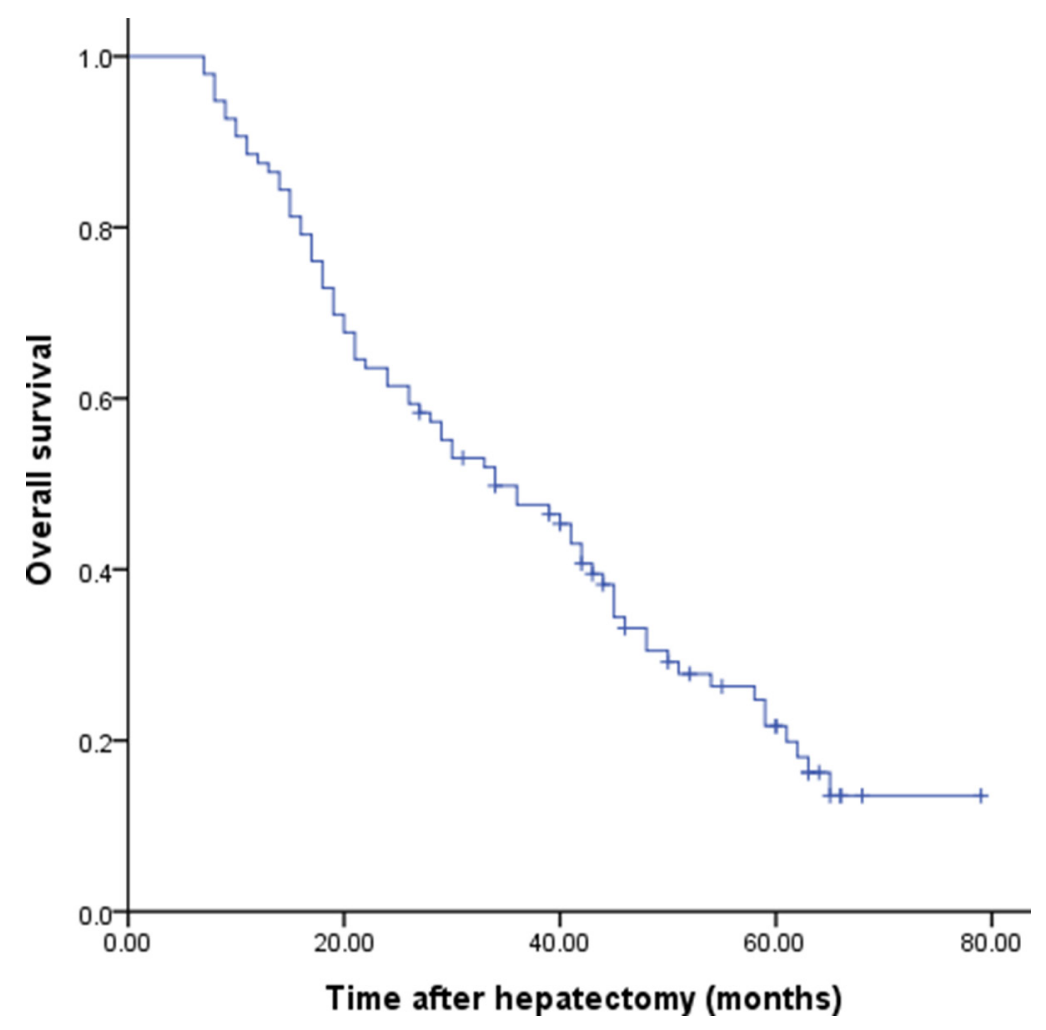

Figure 1: Cumulative overall survival for patients who underwent resection for hepatic metastasis from gastric cancer. 
$11.4 \%$ of patients with major complications in current study, it is possible that failure to detect a clinically significant difference represents a type-II error.

Percutaneous radiofrequency ablation (RFA) is generally accepted as a safe, effective and minimally invasive treatment for patients with CLM [36]. However, few studies have focused on RFA for HMGC. RFA may contribute to local control of single liver-only metastatic lesions [37]. No reliable data on the comparative therapeutic efficacy of RFA and hepatic resection for resectable HMGC are available at present, and therefore RFA should not be recommended as an alternative to surgical resection at this disease stage.

Recurrence following surgical resection of $\mathrm{HMGC}$ is common and mostly occurs in the remaining liver tissue. Repeat hepatectomy seems beneficial to patients with solitary intrahepatic recurrence [25, 27]. Unfortunately, very few patients are potential candidates for hepatic resection because of extensive metastases [27].

The efficacy of adjuvant chemotherapy after liver resection of HMGC remains unclear. Qiu et al. [24] reported that patients who received adjuvant chemotherapy had significantly better survival. However, our and other studies [9, 25, 27] were unable to confirm their conclusion. These different findings may be explained by differences in the regimens used, the timing and duration of cytotoxic agent administration, and patient selection between these studies. Unlike CLM, it seems impossible to test the clinical significance of adjuvant chemotherapy for HMGC in a prospective manner because of the rarity of candidates [27].

The study has some limitations, including the retrospective nature and possible bias in patient selection. More data are needed to further verify the conclusion of the present study.

In conclusion, this large-cohort study has demonstrated that surgical resection for HMGC is feasible and beneficial to long-term survival in selected patients.

\section{MATERIALS AND METHODS}

\section{Patients}

Included in this study were 96 patients who underwent surgical resection for HMGC between January 2001 and January 2012 in six medical institutions in China. The study was approved by the ethics committee of each contributing institution. Written informed consent forms were not required from the patients due to the retrospective approach of the study. In general, surgical resection of HMGC followed the following criteria: (1) curative resection (microscopic tumor removal based on the histopathologic evaluation) of the primary tumor and liver metastasis thought to be technically accessible; and (2) no sign of concomitant extrahepatic metastasis on preoperative imaging. Data were collected retrospectively by reviewing the medical records, including patient age and sex at hepatic resection; pathological characteristics of the primary gastric cancer and hepatic metastasis; and short- and long-term outcomes after surgery. Postoperative mortality was defined as any death occurring within 30 days of surgery or within the same hospital stay. Postoperative complications were defined as occurrence of any medical or surgical complication during the hospital stay and graded according to the Clavien-Dindo classification [38]. The primary tumor stage and regional lymph node status were classified according to the 7 th edition of the International Union Against Cancer of gastric cancer [39]. The types of hepatectomy were classified in accordance with the Brisbane 2000 nomenclature [40].

\section{Statistical analysis}

Overall survival was determined by Kaplan-Meier analysis. Factors related to survival selected by univariate analysis with $P<0.05$ were entered into a multivariate analysis using Cox proportional hazard regression model to determine the independent risk factors for survival. All statistical analyses were performed using SPSS for Windows (version 11.0; SPSS Institute, Chicago, IL, USA). $P<0.05$ was considered statistically significant.

\section{Abbreviations}

HMGC: hepatic metastasis from gastric cancer; OS: overall survival; HR: hazard ratio; CI: confidence interval; CLM: colorectal liver metastasis; RFA: radiofrequency ablation.

\section{Authors' contributions}

Conception/Design: Yanming Zhou. Provision of study materials or patients: Ailin Song, Xiaofeng Zhang, Feng Yu, Debang Li, Wenyu Shao, Yanmng Zhou. Collection and/or extract data: Ailin Song, Xiaofeng Zhang, Feng Yu, Debang Li, Wenyu Shao, Yanmng Zhou. Data analysis and statistical guidance: Ailin Song, Yanming Zhou. Final approval of the manuscript: Ailin Song, Xiaofeng Zhang, Feng Yu, Debang Li, Wenyu Shao, Yanmng Zhou

\section{CONFLICTS OF INTEREST}

The authors indicated no financial relationships.

\section{REFERENCES}

1. Kerkar SP, Kemp CD, Avital I. Liver resections in metastatic gastric cancer. HPB (Oxford). 2010; 12:589-96.

2. Ambiru S, Miyazaki M, Ito H, Nakagawa K, Shimizu H, Yoshidome H, Shimizu Y, Nakajima N. Benefits and limits of hepatic resection for gastric metastases. Am J Surg. 2001; 181:279-83. 
3. Imamura H, Matsuyama $\mathrm{Y}$, Shimada R, Kubota M, Nakayama A, Kobayashi A, Kitamura H, Ikegami T, Miyagawa SI, Kawasaki S. A study of factors influencing prognosis after resection of hepatic metastases from colorectal and gastric carcinoma. Am J Gastroenterol. 2001; 96:3178-84.

4. Okano K, Maeba T, Ishimura K, Karasawa Y, Goda F, Wakabayashi H, Usuki H, Maeta H. Hepatic resection for metastatic tumors from gastric cancer. Ann Surg. 2002; 235:86-91.

5. Zacherl J, Zacherl M, Scheuba C, Steininger R, Wenzl E, Mühlbacher F, Jakesz R, Längle F. Analysis of hepatic resection of metastasis originating from gastric adenocarcinoma. J Gastrointest Surg. 2002; 6:682v689.

6. Sakamoto Y, Ohyama S, Yamamoto J, Yamada K, Seki M, Ohta K, Kokudo N, Yamaguchi T, Muto T, Makuuchi M. Surgical resection of liver metastases of gastric cancer: an analysis of a 17-year experience with 22 patients. Surgery. 2003; 133:507-11.

7. Shirabe K, Shimada M, Matsumata T, Higashi H, Yakeishi Y, Wakiyama S, Ikeda Y, Ezaki T, Fukuzawa S, Takenaka K, Kishikawa K, Ikeda T, Taguchi K, et al. Analysis of the prognostic factors for liver metastasis of gastric cancer after hepatic resection: a multi-institutional study of the indications for resection. Hepatogastroenterology. 2003; 50:1560-63.

8. Adam R, Chiche L, Aloia T, Elias D, Salmon R, Rivoire M, Jaeck D, Saric J, Le Treut YP, Belghiti J, Mantion G, Mentha G, and Association Française de Chirurgie. Hepatic resection for noncolorectal nonendocrine liver metastases: analysis of 1,452 patients and development of a prognostic model. Ann Surg. 2006; 244:524-35.

9. Sakamoto Y, Sano T, Shimada K, Esaki M, Saka M, Fukagawa T, Katai H, Kosuge T, Sasako M. Favorable indications for hepatectomy in patients with liver metastasis from gastric cancer. J Surg Oncol. 2007; 95:534-39.

10. Cheon SH, Rha SY, Jeung HC, Im CK, Kim SH, Kim HR, Ahn JB, Roh JK, Noh SH, Chung HC. Survival benefit of combined curative resection of the stomach (D2 resection) and liver in gastric cancer patients with liver metastases. Ann Oncol. 2008; 19:1146-53.

11. Morise Z, Sugioka A, Hoshimoto S, Kato T, Ikeda M, Uyama I, Horiguchi A, Miyakawa S. The role of hepatectomy for patients with liver metastases of gastric cancer. Hepatogastroenterology. 2008; 55:1238-41.

12. Thelen A, Jonas S, Benckert C, Lopez-Hänninen E, Neumann U, Rudolph B, Schumacher G, Neuhaus P. Liver resection for metastatic gastric cancer. Eur J Surg Oncol. 2008; 34:1328-34.

13. Ueda K, Iwahashi M, Nakamori M, Nakamura M, Naka T, Ishida K, Ojima T, Yamaue H. Analysis of the prognostic factors and evaluation of surgical treatment for synchronous liver metastases from gastric cancer. Langenbecks Arch Surg. 2009; 394:647-53.
14. Makino H, Kunisaki C, Izumisawa $Y$, Tokuhisa M, Oshima T, Nagano Y, Fujii S, Kimura J, Takagawa R, Kosaka T, Ono HA, Akiyama H, Tanaka K, Endo I. Indication for hepatic resection in the treatment of liver metastasis from gastric cancer. Anticancer Res. 2010; 30:2367-76.

15. Tsujimoto H, Ichikura T, Ono S, Sugasawa H, Hiraki S, Sakamoto N, Yaguchi Y, Hatsuse K, Yamamoto J, Hase K. Outcomes for patients following hepatic resection of metastatic tumors from gastric cancer. Hepatol Int. 2010; 4:406-13.

16. Dittmar Y, Altendorf-Hofmann A, Rauchfuss F, Götz M, Scheuerlein H, Jandt K, Settmacher U. Resection of liver metastases is beneficial in patients with gastric cancer: report on 15 cases and review of literature. Gastric Cancer. 2012; 15:131-36.

17. Garancini M, Uggeri F, Degrate L, Nespoli L, Gianotti L, Nespoli A, Uggeri F, Romano F. Surgical treatment of liver metastases of gastric cancer: is local treatment in a systemic disease worthwhile? HPB (Oxford). 2012; 14:209-15.

18. Miki Y, Fujitani K, Hirao M, Kurokawa Y, Mano M, Tsujie M, Miyamoto A, Nakamori S, Tsujinaka T. Significance of surgical treatment of liver metastases from gastric cancer. Anticancer Res. 2012; 32:665-70.

19. Schildberg CW, Croner R, Merkel S, Schellerer V, Müller V, Yedibela S, Hohenberger W, Peros G, Perrakis A. Outcome of operative therapy of hepatic metastatic stomach carcinoma: a retrospective analysis. World J Surg. 2012; $36: 872-78$.

20. Takemura N, Saiura A, Koga R, Arita J, Yoshioka R, Ono Y, Hiki N, Sano T, Yamamoto J, Kokudo N, Yamaguchi T. Long-term outcomes after surgical resection for gastric cancer liver metastasis: an analysis of 64 macroscopically complete resections. Langenbecks Arch Surg. 2012; 397:951-57.

21. Wang YN, Shen KT, Ling JQ, Gao XD, Hou YY, Wang XF, Qin J, Sun YH, Qin XY. Prognostic analysis of combined curative resection of the stomach and liver lesions in 30 gastric cancer patients with synchronous liver metastases. BMC Surg. 2012; 12:20.

22. Baek HU, Kim SB, Cho EH, Jin SH, Yu HJ, Lee JI, Bang HY, Lim CS. Hepatic resection for hepatic metastases from gastric adenocarcinoma. J Gastric Cancer. 2013; 13:86-92.

23. Chen L, Song MQ, Lin HZ, Hao LH, Jiang XJ, Li ZY, Chen YX. Chemotherapy and resection for gastric cancer with synchronous liver metastases. World J Gastroenterol. 2013; 19:2097-103.

24. Qiu JL, Deng MG, Li W, Zou RH, Li BK, Zheng Y, Lao XM, Zhou K, Yuan YF. Hepatic resection for synchronous hepatic metastasis from gastric cancer. Eur J Surg Oncol. 2013; 39:694-700.

25. Komeda K, Hayashi M, Kubo S, Nagano H, Nakai T, Kaibori M, Wada H, Takemura S, Kinoshita M, Koga C, 
Matsumoto M, Sakaguchi T, Inoue Y, et al. High survival in patients operated for small isolated liver metastases from gastric cancer: a multi-institutional study. World J Surg. 2014; 38:2692-97.

26. Wang W, Liang H, Zhang H, Wang X, Xue Q, Zhang R. Prognostic significance of radical surgical treatment for gastric cancer patients with synchronous liver metastases. Med Oncol. 2014; 31:258.

27. Kinoshita T, Kinoshita T, Saiura A, Esaki M, Sakamoto H, Yamanaka T. Multicentre analysis of long-term outcome after surgical resection for gastric cancer liver metastases. Br J Surg. 2015; 102:102-07.

28. Shinohara T, Maeda Y, Hamada T, Futakawa N. Survival benefit of surgical treatment for liver metastases from gastric cancer. J Gastrointest Surg. 2015; 19:1043-51.

29. Tiberio GA, Baiocchi GL, Morgagni P, Marrelli D, Marchet A, Cipollari C, Graziosi L, Ministrini S, Vittimberga G, Donini A, Nitti D, Roviello F, Coniglio A, de Manzoni G. Gastric cancer and synchronous hepatic metastases: is it possible to recognize candidates to $\mathrm{R} 0$ resection? Ann Surg Oncol. 2015; 22:589-96.

30. Oki E, Tokunaga S, Emi Y, Kusumoto T, Yamamoto M, Fukuzawa K, Takahashi I, Ishigami S, Tsuji A, Higashi H, Nakamura T, Saeki H, Shirabe K, et al, and Kyushu Study Group of Clinical Cancer. Surgical treatment of liver metastasis of gastric cancer: a retrospective multicenter cohort study (KSCC1302). Gastric Cancer. 2016; 19:968-76.

31. Tiberio GA, Ministrini S, Gardini A, Marrelli D, Marchet A, Cipollari C, Graziosi L, Pedrazzani C, Baiocchi GL, La Barba G, Roviello F, Donini A, de Manzoni G, Italian Research Group for Gastric Cancer. Factors influencing survival after hepatectomy for metastases from gastric cancer. Eur J Surg Oncol. 2016; 42:1229-35.

32. Markar SR, Mackenzie H, Mikhail S, Mughal M, Preston SR, Maynard ND, Faiz O, Hanna GB. Surgical resection of hepatic metastases from gastric cancer: outcomes from national series in England. Gastric Cancer. 2017; 20:379-86.

33. Petrelli F, Coinu A, Cabiddu M, Ghilardi M, Borgonovo K, Lonati V, Barni S. Hepatic resection for gastric cancer liver metastases: A systematic review and meta-analysis. J Surg Oncol. 2015; 111:1021-27.

34. Markar SR, Mikhail S, Malietzis G, Athanasiou T, Mariette C, Sasako M, Hanna GB. Influence of Surgical Resection of Hepatic Metastases From Gastric Adenocarcinoma on Longterm Survival: Systematic Review and Pooled Analysis. Ann Surg. 2016; 263:1092-101.

35. Odermatt M, Miskovic D, Flashman K, Khan J, Senapati A, O'Leary D, Thompson M, Parvaiz A. Major postoperative complications following elective resection for colorectal cancer decrease long-term survival but not the time to recurrence. Colorectal Dis. 2015; 17:141-49.

36. Stang A, Oldhafer KJ, Weilert H, Keles H, Donati M. Selection criteria for radiofrequency ablation for colorectal liver metastases in the era of effective systemic therapy: a clinical score based proposal. BMC Cancer. 2014; 14:500.

37. Chen J, Tang Z, Dong X, Gao S, Fang H, Wu D, Xiang D, Zhang S. Radiofrequency ablation for liver metastasis from gastric cancer. Eur J Surg Oncol. 2013; 39:701-06.

38. Dindo D, Demartines N, Clavien PA. Classification of surgical complications: a new proposal with evaluation in a cohort of 6336 patients and results of a survey. Ann Surg. 2004; 240:205-13.

39. Sobin L, Gospodarowicz M, Wittekind C. TNM Classification of Malignant Tumours. 7th ed. New York: Wiley-Blackwell; 2009.

40. Strasberg SM. Nomenclature of hepatic anatomy and resections: a review of the Brisbane 2000 system. J Hepatobiliary Pancreat Surg. 2005; 12:351-55. 